\title{
What Can General Medical Providers Do for Hospitalized Patients with Alcohol Dependence After Discharge?
}

\author{
Katharine A. Bradley, MD, MPH $H^{1,2,3,4}$ and Emily C. Williams, PhD, MPH \\ ${ }^{1}$ Health Services Research \& Development (HSR\&D), Veterans Affairs (VA) Puget Sound Health Care System, Seattle, WA, USA; ${ }^{2}$ General \\ Medicine Service, Veterans Affairs (VA) Puget Sound Health Care System, Seattle, WA, USA; ${ }^{3}$ Center of Excellence in Substance Abuse \\ Treatment and Education, Veterans Affairs (VA) Puget Sound Health Care System, Seattle, WA, USA; ${ }^{4}$ Department of Medicine, University of \\ Washington, Seattle, WA, USA.
}

$\mathrm{J}$ Gen Intern Med 25(10):1000-2

DOI: $10.1007 / \mathrm{s} 11606-010-1441-7$

(c) Society of General Internal Medicine 2010

I $\mathrm{n}$ the study by Bertholet et al. in this issue of $\mathrm{JGIM},{ }^{1}$ most medical inpatients who screened positive for unhealthy drinking and enrolled in a trial of a brief alcohol intervention had alcohol dependence. ${ }^{1}$ The trial, reported previously, ${ }^{2}$ found no benefit of the single brief intervention, and $67 \%$ of participants were still drinking heavily and/or having symptoms due to drinking 1 year later. ${ }^{1}$ Although the secondary analyses reported by Bertholet et al. identified three predictor measures that were associated with subsequent improved drinking outcomes, only one of the measures-alcohol treatment in the year after hospitalization-could be influenced by medical providers. The other two predictors of improved outcomes were patient characteristics at the time of admission. $^{1}$

Alcohol treatment improves outcomes for alcohol dependence, ${ }^{3,4}$ but most individuals with alcohol dependence never receive specialized treatment. ${ }^{5}$ As few as $11 \%$ of patients with alcohol dependence are referred for specialty treatment, ${ }^{6}$ and when they are referred, many patients do not engage in treatment. ${ }^{7}$ In a national survey, $85 \%$ of people with prior alcohol dependence never sought alcohol treatment. ${ }^{5}$ Among the $15 \%$ who had sought help, less than half reported formal treatment, and most attended 12-step programs such as Alcoholics Anonymous. ${ }^{5}$ The 2008 National Household Survey on Drug Use and Health found that most people with alcohol dependence did not think they needed treatment. ${ }^{8}$ Among individuals with alcohol dependence who felt they needed treatment, the two most common reasons for not receiving it were: (1) not being ready to stop drinking, and (2) not having health insurance coverage and not being able to

The views expressed in this article are those of the authors and do not reflect the position or policy of the Department of Veterans Affairs or the University of Washington.

Alcohol abuse and dependence are increasingly recognized as a single condition, alcohol use disorder with a spectrum of severity; however, we use the simpler term alcohol dependence to describe this spectrum in this article. $^{30,31}$

Published online July 15, 2010 afford treatment. ${ }^{8}$ Barriers to alcohol treatment have led to increased calls for management of alcohol dependence in nonspecialty addiction settings and treatments that can engage patients with alcohol dependence over extended periods of time. ${ }^{9-11}$

Although only a minority of medical inpatients with alcohol dependence will receive specialized alcohol treatment, many will see general internists after discharge. This provides an ideal opportunity to engage patients in discussions about their drinking. While the efficacy of single brief interventions for alcohol dependence is not clear, ${ }^{12,13}$ two efficacious approaches to management of alcohol dependence can be integrated into general medical settings and may be acceptable to patients who do not engage in alcohol treatment.

Repeated outpatient interventions by medical providers have been shown to decrease drinking in patients with alcohol dependence. ${ }^{14,15}$ One trial recruited male VA inpatients hospitalized for alcohol-related medical problems. Participants were not willing to enter abstinence-oriented alcohol treatment, but agreed to attend general medical visits to monitor their drinking and health problems. ${ }^{14}$ Intervention patients saw a primary care provider monthly or more often as needed to monitor their medical condition. Visits included review of recent drinking, feedback on objective measures of health impacted by drinking (e.g., gamma glutamyl transferase or blood pressure), and encouragement to decrease drinking. After 2 years, intervention patients were more likely than usual care patients to report abstinence (74\% vs $47 \%$; p $=0.02) .{ }^{14}$ Another observational study reported markedly decreased drinking among alcoholdependent patients with cirrhosis who received repeated medical visits that combined empathetic discussions of their drinking with monitoring laboratory tests. ${ }^{7}$ Repeated telephone interventions over 6 weeks also reduced drinking in men in a randomized controlled trial of outpatients with alcohol dependence. ${ }^{15}$ Finally, in the COMBINE trial of medications for alcohol dependence, placebo combined with repeated medical visits was not statistically different from specialized alcohol treatment for improving drinking outcomes. ${ }^{16,17}$ Taken together, these studies suggest that repeated discussions with patients about their drinking and its relation to their health is one effective approach to managing alcohol dependence when specialized alcohol treatment is not an acceptable option.

Four medications-disulfiram, naltrexone, acamprosate, and topiramate-are efficacious for treatment of alcohol dependence and recommended for use in medical settings, ${ }^{18}$ although topiramate has not been FDA approved for treatment 
of alcohol dependence. Naltrexone and topiramate have been studied more than other medications when provided with minimal behavioral support, as is practical in most medical settings. ${ }^{19}$ The COMBINE trial revealed that naltrexone, provided in combination with medication management, was as efficacious as a state-of-the-art specialized alcohol treatment. ${ }^{16}$ At medication management visits every 1-4 weeks, medical providers assessed side effects of and adherence to medications, reviewed recent drinking, and encouraged patients to attend Alcoholics Anonymous. ${ }^{16}$ Naltrexone, which comes in an oral or injectable (longacting) form, ${ }^{20}$ appears effective whether or not patients are abstinent, although efficacy appears greatest in patients who abstain for 7 days before initiating treatment. ${ }^{21}$ In patients with major depression as well as alcohol dependence, a recent trial suggested that combined naltrexone and an SSRI improves alcohol dependence outcomes. ${ }^{22,23}$ Topiramate was also efficacious for decreasing alcohol consumption when combined with weekly medical visits that were modeled after depression care management programs. ${ }^{24,25}$ Of note, topiramate was efficacious even though it was studied in patients who continued to drink heavily at the time of enrollment. ${ }^{24}$ Other medications that may reduce drinking among patients with alcohol dependence include baclofen, ${ }^{26}$ gabapentin, ${ }^{27}$ and ondansetron. ${ }^{19,28}$

Twenty years ago, the Institute of Medicine called for a broadening of the base of alcohol treatment. ${ }^{29}$ While much attention has been focused on alcohol screening and brief intervention, general internists also need to actively manage alcohol dependence in patients who do not respond to brief interventions or engage in specialty addictions care, including those recently discharged from the hospital. ${ }^{10,11,18}$ As models for integrating mental health care into the patient-centered medical home are further developed, it will be essential to design systems that can support frequent medical visits and management of medications for patients with alcohol dependence.

Conflict of Interest: Dr. Bradley owns stock in Johnson and Johnson, which owns a subsidiary that makes Topiramate. Topiramate has been available in generic form since 2009.

The authors certify that we have no other affiliation with or financial involvement in any organization or entity with a direct financial interest in the subject matter or materials discussed in the manuscript (e.g., employment, consultancies, stock ownership, honoraria).

Corresponding Author: Katharine A. Bradley, MD, MPH; Health Services Research \& Development (HSR\&D), Veterans Affairs (VA) Puget Sound Health Care System, 1100 Olive Way, Suite 1400, Seattle, WA 98101, USA (e-mail: Katharine.bradley@va.gov).

\section{REFERENCES}

1. Bertholet N, Cheng DM, Palfai TP, Saitz R. Factors associated with favorable drinking outcome at 12 months after hospitalization in a prospective cohort study of inpatients with unhealthy alcohol use. J Gen Intern Med. 2010; doi:10.1007/s11606-010-1382-1.

2. Saitz R, Palfai TP, Cheng DM, et al. Brief intervention for medical inpatients with unhealthy alcohol use: a randomized, controlled trial. Ann Intern Med. 2007;146(3):167-76.
3. Weisner C, Matzger H, Kaskutas LA. How important is treatment? Oneyear outcomes of treated and untreated alcohol-dependent individuals. Addiction. 2003;98(7):901-11.

4. Dawson DA, Grant BF, Stinson FS, Chou PS. Estimating the effect of help-seeking on achieving recovery from alcohol dependence. Addiction. 2006;101(6):824-34.

5. Cohen E, Feinn R, Arias A, Kranzler HR. Alcohol treatment utilization: findings from the National Epidemiologic Survey on Alcohol and Related Conditions. Drug Alcohol Depend. 2007;86(2-3):214-21.

6. McGlynn EA, Asch SM, Adams JL, et al. The quality of health care delivered to adults in the United States. N Engl J Med. 2003;348 (26):2635-45.

7. Lieber CS, Weiss DG, Groszmann R, Paronetto F, Schenker S. I. Veterans Affairs Cooperative Study of polyenylphosphatidylcholine in alcoholic liver disease: effects on drinking behavior by nurse/physician teams. Alcohol Clin Exp Res. 2003;27(11):1757-64.

8. Substance Abuse and Mental Health Services Administration. Results from the 2008 National Survey on Drug Use and Health: National Findings 2009; http://www.oas.samhsa.gov/nsduh/2k8nsduh/ 2k8Results.cfm\#7.3.

9. McKay JR. Is there a case for extended interventions for alcohol and drug use disorders? Addiction. 2005;100(11):1594-1610.

10. McLellan AT. Reducing heavy drinking: a public health strategy and a treatment goal? J Subst Abuse Treat. 2007;33(1):81-3.

11. Willenbring ML. Medications to treat alcohol dependence: adding to the continuum of care. JAMA. 2007;298(14):1691-2.

12. Guth S, Lindberg SA, Badger GJ, Thomas CS, Rose GL, Helzer JE. Brief intervention in alcohol-dependent versus nondependent individuals. J Stud Alcohol Drugs. 2008;69(2):243-50.

13. Moyer A, Finney JW, Swearingen CE, Vergun P. Brief interventions for alcohol problems: a meta-analytic review of controlled investigations in treatment-seeking and non-treatment-seeking populations. Addiction. 2002;97:279-92.

14. Willenbring ML, Olson DH. A randomized trial of integrated outpatient treatment for medically ill alcoholic men. Arch Intern Med. 1999;159 (16): 1946-52

15. Brown RL, Saunders LA, Bobula JA, Mundt MP, Koch PE. Randomized-controlled trial of a telephone and mail intervention for alcohol use disorders: 3-month drinking outcomes. Alcohol Clin Exp Res. 2007;31 (8): 1372-9.

16. Anton RF, O'Malley SS, Ciraulo DA, et al. Combined pharmacotherapies and behavioral interventions for alcohol dependence: the COMBINE study: a randomized controlled trial. JAMA. 2006;295(17):2003-17.

17. Ernst DB, Pettinati HM, Weiss RD, Donovan DM, Longabaugh R. An intervention for treating alcohol dependence: relating elements of Medical Management to patient outcomes with implications for primary care. Ann Fam Med. 2008;6(5):435-40

18. National Institute on Alcohol Abuse and Alcoholism, US Department of Health and Human Services, National Institute of Health. Helping Patients Who Drink Too Much: A Clinician's Guide (updated 2005 guide). 2007.

19. Johnson BA. Medication treatment of different types of alcoholism. Am J Psychiatry. 2010;167(6):630-9.

20. Lee JD, Grossman E, Dirocco D, et al. Extended-release naltrexone for treatment of alcohol dependence in primary care. J Subst Abuse Treat. 2010.

21. Garbutt JC, Kranzler HR, O'Malley SS, et al. Efficacy and tolerability of long-acting injectable naltrexone for alcohol dependence: a randomized controlled trial. Jama. 2005;293(13):1617-25.

22. Pettinati HM, Oslin DW, Kampman KM, et al. A double-blind, placebocontrolled trial combining sertraline and naltrexone for treating cooccurring depression and alcohol dependence. Am J Psychiatry. 2010;167(6):668-75.

23. Patkar AA, Li TK. Treatments for alcohol dependence: rethinking the role of comorbidity and clinical subtypes. Am J Psychiatry. 2010;167(6):620-2.

24. Johnson BA, Rosenthal N, Capece JA, et al. Topiramate for treating alcohol dependence: a randomized controlled trial. JAMA. 2007;298 (14):1641-51.

25. Johnson BA, Ait-Daoud N, Bowden CL, et al. Oral topiramate for treatment of alcohol dependence: a randomised controlled trial. Lancet. 2003;361(9370): 1677-85.

26. Addolorato G, Leggio L, Ferrulli A, et al. Effectiveness and safety of baclofen for maintenance of alcohol abstinence in alcohol-dependent patients with liver cirrhosis: randomised, double-blind controlled study. Lancet. 2007;370(9603):1915-22. 
27. Myrick H, Malcolm R, Randall PK, et al. A double-blind trial of gabapentin versus lorazepam in the treatment of alcohol withdrawal. Alcohol Clin Exp Res. 2009;33(9):1582-8.

28. Johnson BA. Update on neuropharmacological treatments for alcoholism: scientific basis and clinical findings. Biochem Pharmacol. 2008;75(1):34-56.

29. Institute of Medicine. Broadening the Base of Treatment for Alcoho Problems: A Report of the Committee for the Study of Treatment and Rehabilitation for Alcoholism. Washington DC: National Academy Press; 1990.
30. American Psychiatric Association. Diagnostic and Statistical Manual of Mental Disorders, 5th Edition Development (DSM-5 Development). 2010; http://www.dsm5.org/ProposedRevisions /Pages/proposedrevision. aspx?rid=452, June 20, 2010.

31. Keyes KM, Geier T, Grant BF, Hasin DS. Influence of a drinking quantity and frequency measure on the prevalence and demographic correlates of DSM-IV alcohol dependence. Alcohol Clin Exp Res. 2009;33(5):761-71. 